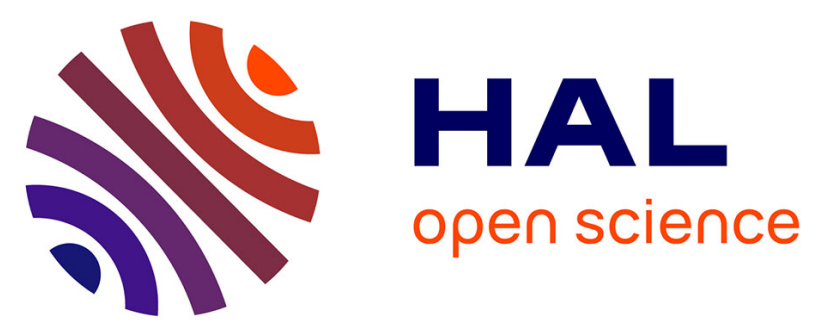

\title{
Improving Carry-Out Operations of Inbound Containers Using Real-Time Information on Truck Arrival Times
}

\author{
Sanghyuk Yi, Lin Gui, Kap Hwan Kim
}

\section{To cite this version:}

Sanghyuk Yi, Lin Gui, Kap Hwan Kim. Improving Carry-Out Operations of Inbound Containers Using Real-Time Information on Truck Arrival Times. IFIP International Conference on Advances in Production Management Systems (APMS), Aug 2018, Seoul, South Korea. pp.457-463, 10.1007/9783-319-99704-9_56. hal-02164882

\section{HAL Id: hal-02164882 \\ https://hal.inria.fr/hal-02164882}

Submitted on 25 Jun 2019

HAL is a multi-disciplinary open access archive for the deposit and dissemination of scientific research documents, whether they are published or not. The documents may come from teaching and research institutions in France or abroad, or from public or private research centers.
L'archive ouverte pluridisciplinaire HAL, est destinée au dépôt et à la diffusion de documents scientifiques de niveau recherche, publiés ou non, émanant des établissements d'enseignement et de recherche français ou étrangers, des laboratoires publics ou privés. 


\title{
Improving Carry-out Operations of Inbound Containers using Real-time Information on Truck Arrival Times
}

\author{
Sanghyuk Yi ${ }^{1,2[0000-0002-4944-4230]}$, Lin Gui ${ }^{2}$, and Kap Hwan Kim²[0000-0002-9001-5852] \\ ${ }^{1}$ University of Bremen, Hochschulring 20, 28359 Bremen, Germany \\ ${ }^{2}$ Pusan National University, Busandaehak-ro 63 beon-gil 2, 46241 Busan, Republic of Korea \\ yisanghyok, kapkim@pusan.ac.kr
}

\begin{abstract}
Multiple inbound containers are piled up at the same stack in container terminals, which causes re-handles during the retrieval or carry-out process by road trucks. This inefficiency of the retrieval operation comes from the fact that the retrieval sequence of inbound containers is extremely uncertain and the retrieval sequence is not from the top to the bottom. This study discusses how the re-handling operations can be reduced by utilizing information on the estimated truck arrival times which may be collected from GPS in a smartphone owned by the truck driver. Algorithms for scheduling the pre-marshaling operation and determining the storage locations of re-handled containers are proposed. This study relaxed the constraint that a yard crane may relocate a container into another slots only in the same bay. The performances of the proposed algorithms are compared with each other by simulation studies.
\end{abstract}

Keywords: Truck Arrival Information, Container Terminal, Re-marshaling, Inbound Containers, Simulation.

\section{Introduction}

At container terminals, when an inbound container to be picked up (target container) is not at the top of a stack, then all the containers placed on the top of the target one have to be relocated to other stacks, which is unproductive and called re-handling operation. The re-handling operation is due to the fact that the positions of the containers do not are matched with the retrieval sequence of containers. When containers are positioned at the locations where no re-handlings are necessary, we say that the containers are well placed.

There have been two types of previous studies on container re-handling problems in container yards. The first one is the Container (Block) Relocation Problem (CRP or $\mathrm{BRP}$ ) where, for a given priority of containers for retrievals, the container to be retrieved next and the locations of the relocated containers for the retrieval should be determined [1,3,6]. The other is the Container Pre-Marshalling Problem (CPMP) in which, for a given priority of containers for the retrieval, containers are relocated in advance (before trucks arrive at the yard) so that they are well placed [2,5,7]. Related to utilizing the information of truck arrival times, the connection between container relocation and truck arrival sequence is presented [8]. Recently, the container relocation 
problem with the truck appointment system was combined [6]. They introduced a CRP model under the assumption that container retrieval times are provided in terms of time windows of specific length. In [4], the yard management by utilizing the real-time location information of trucks was firstly discussed.

This paper extends the pre-marshalling operation with real-time information of truck arrival by considering the gantry move of yard crane during pre-marshalling or re-handling operations, which provides better candidate stacks with blocking containers to be move to. The objective of this paper is to minimize the number of re-handles and the turnaround time of trucks for inbound containers considering estimated arrival information of trucks.

\section{Estimating the Possibility of Re-handles}

As illustrated in Fig. 1, a terminal operation system (TOS) receives the real-time position of each truck from real-time truck locating systems (RTLSs) with the support of information technologies (ex. GPS). Then, TOS will estimate the truck's expectation and standard deviation of the remaining time before the arrival (RTBA) which can be derived by using its expected arrival time and the current time when collecting information. Whenever a yard crane becomes idle, TOS will issue pre-marshalling orders.

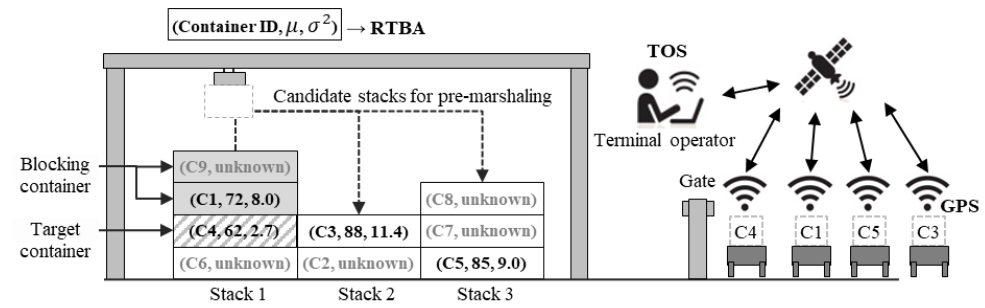

Fig. 1. Real-time truck locating system (RTLS) and information on their arrivals

This study assumes the uncertainty of an RTBA of a container which is represented by a random variable $X$ following a general distribution with parameters $\mu$ and $\sigma$ like equation (1). In equation (1), $f$ represents a probability density function of $X$ where $\mu$ and $\sigma$ denote the expectation and the standard deviation of RTBA, respectively.

$X \sim f\left(\mu, \sigma^{2}\right)$

The container to be relocated to the topmost position during the re-marshalling process is called 'target container,' while containers on the top of the target container are called 'blocking containers.' For a pair of containers in the same stack, let $X_{l} \sim f\left(\mu_{l}, \sigma_{l}^{2}\right)$ for container $l$ in a lower tier and $X_{h} \sim f\left(\mu_{h}, \sigma_{h}^{2}\right)$ for a container $h$ in a higher tier. the probability that container $l$ will be retrieved earlier than container $h$ can be expressed in equation (2) where the variance of RTBA is assumed to be proportional to the expectation of RTBA. 
$P\left(X_{l}<X_{h}\right)=\Phi\left(\frac{\mu_{h}-\mu_{l}}{\sqrt{\mu_{h} \sigma_{h}^{2}+\mu_{l} \sigma_{l}^{2}}}\right)$

A badly-placed container (container $l$ ) is defined as a container which has at least one container (container $h$ ) at a higher tier of the same stack such that

$P\left(X_{l}<X_{h}\right) \geq \delta$

where the threshold $\delta$ is a decision parameter that will be found by using a simulation experiment.

Among all the badly-placed containers, only those whose expected value of RTBA is shorter than a lead time for pre-marshalling $(T)$ will be included into the list of containers to be pre-marshalled.

\section{Pre-marshalling Algorithm for a Yard Crane with Multi-bay Coverage}

The overall pre-marshalling procedure is described as follow:

Step 1: Select the target container for pre-marshalling operation

Step 2: Select the stack for a blocking container to be moved to

The target container of Step 1 is the badly-placed one with shorter RTBA by using equation (1) and (2). After selecting the target container, the target stacks onto which blocking containers are to be moved must be determined in Step 2. The main idea of selecting the target stack is that the blocking container should be moved to a stack where there is a lower possibility of creating additional re-handles. Let

$P\left(s_{i}, b\right)=\Phi\left(\frac{\mu_{\min }\left(s_{i}\right)-\mu_{b}}{\sqrt{\mu_{\min }\left(s_{i}\right) \sigma_{\min }^{2}\left(s_{i}\right)+\mu_{b} \sigma_{b}^{2}}}\right)$

where $\mu_{b}$ and $\sigma_{b}^{2}$ represent the mean value and the variance of RTBA of the blocking container (container $b$ ), respectively, and $\mu_{\min }\left(s_{i}\right)$ and $\sigma_{\min }^{2}\left(s_{i}\right)$ represent the mean and the variance of RTBA of the container whose mean RTBA is smallest in stack $i$. Then, $P\left(s_{i}, b\right)$ implies the probability that the relocated container is retrieved earlier than the container whose mean RTBA is smallest in stack $i$.

In general, the re-handles of a yard crane occur within a bay without its gantry move. In the case of conventional equipment such as a RTGC (Rubber Tired Gantry Crane), it takes quite long time to move in the gantry direction. Thus, it makes sense to rehandle containers within a bay. However, in the case of an automated RMGC (Rail Mounted Gantry Crane), there is no need to restrict the gantry move within a bay during re-handling operation. Therefore, this study allows yard cranes to be able to relocate a container into any slot within the nearest $n$ bays during pre-marshaling and re-handling operation. 
Let the set of stacks, excluding the stack where container $b$ is currently located, whose value of $\mathrm{P}\left(s_{i}, b\right)$ is larger than or equal to a threshold value $\delta$ be $S^{W}$ and those whose value of $\mathrm{P}\left(s_{i}, b\right)$ is smaller than a threshold value $\delta$ be $S^{B}$. If there exist multiple in $S^{W}$, then select the stack with the smallest value of $P\left(s_{i}, b\right)$. If there exists no such a stack, then select the stack with the largest value of $P\left(s_{i}, b\right)$ in $S^{B}$. The procedure is summarized as follows:

Step 2-1: Select candidate stacks which are located within the coverage range $(n)$ from the target container and have empty slots. Let $S^{W}=\left\{i \mid P\left(s_{i}, b\right) \geq \delta\right\}$. If $S^{W}=$ $\emptyset$, then go to Step 2-3; otherwise, go to Step 2-2.

Step 2-2: $s^{*}(b)=\operatorname{argmin}_{i \in S^{W}} P\left(s_{i}, b\right)$. If there exist multiple candidate stacks, run Tie-Break-Rule and $s^{*}(b)$ is the target stack for container $b$ to be move to. Stop.

Step 2-3: Let $S^{B}=\left\{i \mid P\left(s_{i}, b\right)<\delta\right\} . s^{*}(b)=\operatorname{argmax}_{i \in S^{B}} P\left(s_{i}, b\right)$. If there exist multiple candidate stacks, run Tie-Break-Rule. Stop.

The following rules are used as the Tie-Break-Rule in the order of (1) lowest position; (2) shortest traveling time of yard cranes; (3) random.

\section{Simulation Experiments}

A simulation model was developed for evaluating the proposed algorithm. It was programmed by Tecnomatix Plant Simulation, Siemens PLM Software Inc. For the input data, we collected the field data which represents inbound containers for around 2 months at ' $S$ ' container terminal in Busan, South of Korea. As attributes of a container, container ID, discharging time and retrieval time were used in the simulation.

It is assumed that the layout of a container terminal consists of 10 blocks with 32 bays, 10 rows, 6 tiers. We assume that the utilization of a bay is $80 \%$. That is, the maximum number of containers that can be stored in a bay was restricted to be 48 .

In the experiment, it was assumed that the terminal operator receives the updated information on the expected RTBA for each inbound container in every 10 minutes after the truck starts its travel.

In the simulation program, the terminal operations were assumed as follows: (i) container discharging and retrieving operations have higher priorities than pre-marshalling operations. It means that pre-marshalling operations are carried out only when a yard crane is idle; (ii) if $\mu_{l}>\mu_{h}$, then $\sigma_{l}^{2}>\sigma_{h}^{2}$. That is, the travel time with a longer expectation has a larger variation, which is a reasonable assumption.

Effects of Pre-marshaling Operation. In order to evaluate the effect of the pre-marshalling operation(PM), the cases with PM were compared with those without PM where $T=4,800$ seconds, $\sigma=2.7, \delta=0.52$. Table 1 shows the results of comparison, which estimates that the turnaround time at block per truck can be reduced by $45.0 \%$ by the pre-marshalling operation. In addition, the number of re-handles per container during the retrieving operation(RT) can be reduced by $95.7 \%$, while the total re-handles may increase by around $10.5 \%$. 
Table 1. Effects of pre-marshaling operation.

\begin{tabular}{lcccc}
\hline Type of operation & \multirow{2}{*}{$\begin{array}{c}\text { Truck turnaround } \\
\text { time at block (sec.) }\end{array}$} & \multicolumn{3}{c}{ The number of re-handles per container } \\
\cline { 3 - 5 } & & During PM (1) & During RT (2) & $(1)+(2)$ \\
\hline Case without PM & 551.43 & 0.000 & 1.147 & 1.147 \\
Case with PM & 303.09 & 1.215 & 0.054 & 1.268 \\
\hline
\end{tabular}

In Table 2, the effect of the coverage of yard cranes on the re-handling operation including PM and RT is analyzed. The wider coverage of yard cranes may provide better candidate stacks for a blocking container to be moved to during PM and RT. It means that the relocated blocking containers may have a higher possibility to find a storage location without re-handle. Instead, the longer gantry travel time may result. Table 2 shows that as the coverage of yard cranes becomes wider, the total average number of re-handles is reduced by $22 \%$.

Table 2. Results of pre-marshaling operation considering traveling time of yard crane.

\begin{tabular}{ccccc}
\hline Coverage $(n)$ of & Truck turnaround & \multicolumn{3}{c}{ Number of re-handles per container } \\
\cline { 3 - 5 } yard crane (bays) & time at block (sec.) & During PM (1) & During RT (2) & $(1)+(2)$ \\
\hline 0 & 303.09 & 1.215 & 0.054 & 1.268 \\
1 & 301.92 & 1.169 & 0.049 & 1.218 \\
2 & 301.48 & 1.161 & 0.048 & 1.210 \\
3 & 301.25 & 0.955 & 0.039 & 0.993 \\
\hline
\end{tabular}

Performances for Various Lead time of Pre-marshaling $(\boldsymbol{T})$. Table 3 shows that the performances of the pre-marshalling strategies on the various lead times of pre-marshalling $(T)$ where $\sigma=2.7, \delta=0.52$. As the value of $T$ is smaller, some opportunities for the pre-marshalling can be missed, which leads to increase the turnaround time of trucks at a block with the increase in the number of re-handles during retrieval operation. On the contrary, as the value of $T$ becomes larger, the number of containers, which are premarshalled, increases and thus more re-handles for pre-marshalling occurs. However, those for retrievals slightly decreases.

Table 3. Performances for various lead times for pre-marshalling $(T)$.

\begin{tabular}{ccccc}
\hline \multirow{2}{*}{ (sec.) } & $\begin{array}{c}\text { Truck turnaround } \\
\text { time at block (sec.) }\end{array}$ & \multicolumn{3}{c}{ Number of re-handles per container } \\
\cline { 3 - 5 } & 327.82 & During PM (1) & During RT (2) & $(1)+(2)$ \\
\hline 1,200 & 306.34 & 1.068 & 0.121 & 1.189 \\
2,400 & 306.02 & 1.175 & 0.055 & 1.230 \\
3,600 & 303.09 & 1.215 & 0.055 & 1.254 \\
4,800 & 304.60 & 1.216 & 0.054 & 1.268 \\
6,000 & & & 0.056 & 1.272 \\
\hline
\end{tabular}


Impacts of Uncertainty $(\boldsymbol{\sigma})$ on Re-handles. Table 4 illustrates how the uncertainty of truck arrival influences terminal operations. The higher uncertain truck arrival means that it is difficult to estimate the truck arrival, which makes the possibility of creating additional re-handles lower. Thus, as $\sigma$ increases, the number of re-handles during PM declines, but those during RT rises with the growth of truck turnaround time at block. If $\sigma$ is larger than around 100, then the value of truck turnaround time becomes similar to the case without PM in Table 1, which implies that the information on truck arrivals is less useful.

Table 4. Impacts of uncertainty $(\sigma)$ of arrival times on re-handles.

\begin{tabular}{ccccc}
\hline$\sigma$ & \multirow{2}{*}{$\begin{array}{c}\text { Truck turnaround } \\
\text { time at block (sec.) }\end{array}$} & \multicolumn{3}{c}{ Number of re-handles per container } \\
\cline { 3 - 5 } & 302.54 & During PM (1) & During RT (2) & $(1)+(2)$ \\
\hline 0.1 & 303.09 & 1.223 & 0.047 & 1.269 \\
2.7 & 323.09 & 1.215 & 0.054 & 1.268 \\
10.0 & 376.42 & 1.160 & 0.100 & 1.260 \\
20.0 & $\ldots$ & 1.047 & 0.188 & 1.235 \\
$\ldots$ & 527.92 & $\ldots$ & $\ldots$ & $\ldots$ \\
100.0 & & 0.777 & 0.408 & 1.184 \\
\hline
\end{tabular}

\section{Conclusions}

This paper discusses the pre-marshalling operation for inbound containers by using uncertain truck arrival information. The pre-marshalling algorithm utilizes the uncertainty of truck arrival to reduce the possibility of creating additional re-handles, which leads to decrease the turnaround time of trucks. In addition, we investigate the impact of gantry move of yard cranes during re-handling operation. The simulation model is developed to perform the experiments. The result shows that the pre-marshalling operation can reduce the truck turnaround time by $45.0 \%$ in comparison with the case without it. Moreover, the pre-marshalling strategies in practice are examined. Finally, we discuss the valid degree of uncertainty for the implementation. In further researches, it is essential to collect/define information of container retrieval from various stakeholders and evaluate the validation for its application.

Acknowledgments. This work was supported by Jungseok Logistics Foundation Grant.

\section{References}

1. Caserta, M., Schwarze, S., Voß, S.: A mathematical formulation and complexity considerations for the blocks relocation problem. European Journal of Operational Research 219(1), 96-104 (2012). 
2. Choe, R., Kim, T., Ryu, K.: Crane scheduling for opportunistic remarshaling of containers in an automated stacking yard. Flexible Services and Manufacturing Journal 27(2), 331-349 (2015).

3. Forster, F. Bortfeldt, A.: A tree search procedure for the container relocation problem. Computers \& Operations Research 39(2), 299-309 (2012).

4. Gui, L.: Pre-marshaling inbound containers utilizing truck arrival information with uncertainty. Master Thesis, Pusan National University, Republic of Korea (2016).

5. Huang, S.H., Lin, T.H.: Heuristic algorithms for the container pre-marshaling problems. Computers and Industrial Engineering 62(1), 13-20 (2012).

6. Ku, D.S., Arthanari, T.S.: Container Relocation Problem with time window for container departure. European Journal of Operational Research 252(3), 1031-1039 (2016).

7. Wang, N., Jin, B., Lim, A.: Target-guided algorithms for the container pre-marshaling problem, Omega 53, 67-77 (2015).

8. Zhao, W.J., Goodchild, A., V.: The impact of truck arrival information on container terminal rehandling. Transportation Research Part E 46(3), 327-343 (2010). 